\title{
Factors Associated with Macrosomia among Neonates Delivered at Debre Markos Referral Hospital, Northwest Ethiopia, 2014: A Case Control Study
}

\section{Tamiru Wondie, Dube Jara* and Mulatu Ayana}

Department of Public Health, College of Medicine and Health Science, Debre Markos University, Ethiopia

\begin{abstract}
Introduction: Macrosomia is defined as birth weight of 4,000 gm and above irrespective of gestational age and affects $3-15 \%$ of all pregnancies. Multiple factors are related with fetal macrosomia. The factors associated with macrosomia in Debre Markos Referral Hospital were not well known.

Objective: The main aim of this study was to assess factors associated with macrosomia in Debre Markos Referral Hospital Northwest Ethiopia, 2014.

Methods: An institutional based unmatched case control study design was conducted. A total of 338 macrosomic neonates whose weight is $>=4000 \mathrm{gm}$ were selected for Cases and 676 normal birth weight neonates whose weight is between 2,500-3,999 gm were selected for the controls using simple random sampling technique. Data were collected from the medical records using data collection checklist. The collected data were entered into Epi data version 3.1 computer programs and exported to SPSS version 20 for analysis. Prior to the analysis, the whole data were cleaned; compiled and analyzed using SPSS version 20. Binary logistic regression was used to identify the factors associated with macrosomia. The results of the study were presented by text and tables based on the types of data.

Results: Neonates born from multiparus women were 1.44 times more likely to have macrosomia as compared to neonates born from primiparus women with $95 \% \mathrm{Cl}$ of $\mathrm{AOR}(1.05,1.98)$. Neonates born post term were 3.67 time more likely to have macrosomia as compared to preterm deliveries with $95 \% \mathrm{Cl}$ of $\mathrm{AOR}(1.01,13.32)$. Maternal complications were significantly associated with neonatal birth weight with (Linear by linear $X^{2}$ value $=35.9, p$ - value $0.000)$

Conclusion: Multiparty and post maturity were predictors of macrosomia. Maternal complication were common in macrosomic groups and hence preventing multi parity and post maturity decrease the incidence of macrosomia and its maternal complication.
\end{abstract}

Keywords: Neonates; Macrosomia; Debre markos; Birth weight

\section{Introduction}

The first report of fetal macrosomia in the literature was made by the doctor monk Francois Rabelais in the sixteenth century [1]. A macrosomic infant is generally defined as one with a birth weight greater than the 90th centile for that population, a definition that includes all infants born with a birth weight greater than $4000 \mathrm{gm}$. The incidence of fetal macrosomia varies from one community to another and furthermore has shown temporal changes in the same community .The incidence varies depending on the cutoff value. It, however, occurs in $1-10 \%$ of all deliveries [2].

The different incidence patterns suggest that patient socio-biological factors may play a determinant role in the development of macrosomia. These suggested factors are advanced maternal age, ethnicity, maternal pre-pregnancy weight, gestational weight gain, multi-parity, gestational age, maternal diabetes or obesity, antecedent of a macrosomic delivery, male infant sex and changes in socio-demographic factors are the significant determinants of macrosomic babies [3]

Over the last few decades, macrosomia of the newborn (birth weight $\geq 4,000 \mathrm{~g}$ ) as an adverse pregnancy outcome has been increasing in many parts of the world especially in the developed countries. Several studies have reported that between $15 \%$ and $25 \%$ of women have given birth to macrosomic infants in different populations during the last three decades [3].
The prevalence of macrosomia in developed countries is between $5 \%$ and $20 \%$; however, an increase of $15-25 \%$ has been reported in the past two to three decades, mainly driven by an increase in maternal obesity and diabetes. Although data for the changing prevalence of macrosomia in developing countries are scarce, investigators of one study in China noted an increase from $6 \cdot 0 \%$ in 1994 , to $7 \cdot 8 \%$ in 2005. As the prevalence of diabetes and obesity in women of reproductive age increases in developing countries, a parallel increase in macrosomic births might be expected [4].

Fetal macrosomia is a major contributor to obstetric morbidity. It is an important cause of perinatal morbidity and mortality. Maternal

${ }^{*}$ Corresponding author: Dube Jara, Lecturer of Epidemiology and Biostatistics, Department of Public Health, College of Medicine and Health science, Debre Markos University, Ethiopia, Tel: +251 0913910575; 0947056270; E-mail: jaradube@yahoo.com,duhoney05@gmail.com

Received September 26, 2014; Accepted November 16, 2014; Published November 18, 2014

Citation: Wondie T, Jara D, Ayana M (2014) Factors Associated with Macrosomia among Neonates Delivered at Debre Markos Referral Hospital, Northwest Ethiopia, 2014: A Case Control Study. J Diabetes Metab 5: 468 doi:10.4172/21556156.1000468

Copyright: $\odot 2014$ Wondie T, et al. This is an open-access article distributed under the terms of the Creative Commons Attribution License, which permits unrestricted use, distribution, and reproduction in any medium, provided the original author and source are credited. 
complications include postpartum hemorrhage, chorioamnionitis, prolonged labor, caesarean delivery and prolonged hospital stay and neonatal complication include shoulder dystocia, brachial plexus injury, skeletal injuries, meconium aspiration, perinatal asphyxia, hypoglycemia, hypocalcemia, clavicular fracture, respiratory distress and low Apgar score increase [3,5].

Despite major progress in obstetrics over the last 100 years, the delivery of large fetuses remains a source of anxiety among caregivers because these pregnancies are at increased risk of several perinatal complications, mentioned above [6].

More or less Ethiopia is on a track as to the achievement of the target set by the Millennium Development Goal on under five mortality and infant mortality but there is a gap on achieving a target set on neonatal mortality and maternal mortality as reported by EDHS 2011 ( NMR 37/1,000 live births, MMR 676/100,000 live birth) [7].

One of the factors contributing for both neonatal and maternal morbidity and mortality is macrosomia and its complication. Exploring the factors associated with macrosomia would contribute some for the achievement of the millennium development goal. In particular, Factors associated with macrosomia are not well examined in Debre Markos Referral Hospital. Meanwhile, a better understanding of macrosomic factors in this particular setting is essential for designing specific cost-effective interventions aimed at reducing neonatal and maternal morbidity and mortality related to macrosomia. Therefore, the main aim of this study was to assess factors associated with macrosomia among neonates delivered at Debre Markos Referral Hospital Northwest Ethiopia, 2014.

This study was undertaken to identify the factor associated with fetal macrosomia in Debre Markos Referral Hospital. Once the study is completed, its finding can be used by the Ministry of Health, international aid agencies, non-profit organizations, and other parties in devising effective policies aimed at decreasing neonatal and maternal morbidity and mortality in the this particular setting. The study can also be used as baseline for further study. It can also contribute to the academic discourse within the discipline of public health and most likely will come up with the ideas for future research on the subject.

\section{Methods}

\section{Study setting and period}

The study was conducted from March to April 2014 in the department of Obstetrics and gynecology at Debre Markos Referral Hospital. DMRH was established in 1957 by Emperor Haile sillassie as a memorandum of Leol Mekonnen. It is located 300 and $265 \mathrm{kms}$ away from the capital city of Ethiopia, Addis Ababa and regional city Bahir Dar respectively. The hospital provides health care service for more than 3.5 million peoples including East, West Gojjam, Awi zone of Amhara regional state, and part of Oromia regional state. It provides an average delivery service more than 2500 mothers per year.

\section{Study design and population}

An institutional based unmatched case control study was conducted. The source populations of this study were all neonates delivered at Debre Markos Referral Hospital. The study populations were neonates delivered in Debre Markos Referral Hospital from January $1^{\text {st }} 2009$ to December $31^{\text {st }} 2014$ for both cases and controls. Where cases were macrosomic neonates whose weight was $>=4000 \mathrm{gm}$ and controls were normal birth weight neonates whose weight was between 2.500-3.999 $\mathrm{gm}$. The cases and controls were singleton infants regardless to maternal age, gestational age, number of parity, delivered from January $1^{\text {st }} 2009$ to December $31^{\text {st }} 2014$. Those deliveries complicated with abruptio placenta, placenta praevia, multiple pregnancy and congenital anomaly for both cases and controls were excluded from the study. Neonates with incomplete information were excluded from the study.

\section{Sample size and sampling}

As study was unmatched case control the required sample size was calculated by taking into account the major factor and using the EPI INFO program. In this regard a minimum detectable Odds Ratio (OR) of 2 for macrosomic neonates as compared to controls, a 5\% level of significance (two-sided), a power of $80 \%$ and a one to two allocation ratio of cases to control (1:2) was assumed. The prevalence of normal birth weight among diabetic mother was $6.1 \%$, study done in Iran taken as a reference [8]. Based on the above assumptions, sample size was 1,014 with 338 for cases and 676 for controls. Total number neonates delivered in the hospital from January $1^{\text {st }} 2009$ to December $31^{\text {st }} 2014$ for both cases and controls were identified from delivery registration book. Then the study participants were selected by using simple random sampling technique from a list of case and control groups obtained from registration book. Cases were included in the study up on fulfillment of the case definition criteria for microsomic neonates. Controls were also included up on the fulfillment of the control definition criteria for normal weight neonates. Two controls were included for one case to ensure representativeness of the population from which they were drawn. Neonates with incomplete information were excluded from the study and replaced by a new one selected by simple random sampling from the rest of the neonates in the register to fill the sample.

\section{Variables and measurement}

The dependent variable of the study was Neonatal birth weight status (Macrosomia or normal birth weight) whereas the independent variables were maternal age, residency, gestational age, parity, gravidity, maternal diabetes, sex of the neonate, maternal nutritional status (obesity and weight gain during pregnancy). Apgar score is assessment of new born adaptation immediately after delivery. Low Apgar score is Apgar score of less than 7 at $1^{\text {st }}$ and $5^{\text {th }}$ minute. Parity is Number of previous birth to an infant, alive or dead. Primiparus is mothers who were experienced only one previous birth. Multiparus is mothers who had parity greater than or equal to 2 . Grand Multiparus is mother who had parity greater than 5 . Asphyxia is a newborn an able to breath after delivery. Instrumental Delivery is mode of delivery by using instrument like forceps or vacuum. Macrosomia is newborn baby weighing greater or equal to $4000 \mathrm{gm}$. Pre Term- Delivery before 37 completed weeks. Post Term-Delivery after 42 completed weeks. Term-Delivery after 37 completed weeks and before 42 completed weeks.

\section{Data collection methods}

Data collection checklist of was prepared and data were collected from delivery register log book by trained nurses working outside delivery ward after orientation given by the investigators. People from the card unit was communicated and briefly trained about the process and the requirements. Cards were traced through the registration books and the card numbers were provided to the card unit personnel. Each card was given a specific identity by the investigators. After cards were retrieved, the required information was recorded on the check list/ questionnaires. One day training was given to data collectors about the objective of the study, methods of data collection and how to collect important information. Pretest was conducted on the 5\% (50 charts) of the sample size to ensure consistency and completeness of the checklist. 
Citation: Wondie T, Jara D, Ayana M (2014) Factors Associated with Macrosomia among Neonates Delivered at Debre Markos Referral Hospital, Northwest Ethiopia, 2014: A Case Control Study. J Diabetes Metab 5: 468 doi:10.4172/2155-6156.1000468

Page 3 of 5

The overall data collection process was controlled by the investigators. Data were entered in Epidata computer programs to minimize data entry error.

\section{Data processing and analysis}

The data were entered using Epi data version 3.1 and were exported to SPSS version 20.0 statistical software packages for data cleaning and analysis. Descriptive analysis was conducted to describe number and percentage distribution of important variables. Binary Logistic regression model was used to identify association between outcome variable and explanatory variables. Both bivariate and multivariable logistic regression analysis was used. The crude and adjusted odds ratio together with their corresponding $95 \%$ confidence intervals was computed. A P-value $<0.05$ was considered to declare a result as statistically significant in this study.

\section{Ethical consideration}

Ethical clearance was obtained from College of Medicine and Health Sciences of Debre Markos University. Then officials at different levels in the hospital were communicated through letters from College of Medicine and Health Sciences. The responsible bodies at the wards and registration room were told about the purpose of the study and verbal informed consent was secured. Confidentiality of the information was secured throughout the study process and no unauthorized body access the information.

\section{Result}

\section{Maternal socio demographic characteristics}

A total 1014 neonates were included in the study, of which 338 were cases and 676 were controls. This study indicated that among total respondents of cases and controls $218(64.5 \%)$ and $625(63.2 \%)$ respectively, were rural dwellers while $120(35.5 \%)$ of cases and 249 $(36.8 \%)$ of controls were urban dwellers. Concerning the maternal age $41(12.1 \%)$ of cases and $122(18 \%)$ of controls were age group $<=20 \mathrm{yrs}$, $204(60.4 \%)$ of cases and $411(60.8 \%)$ of controls were from age group 21-30years, 86 (25.4\%) of cases and 134 (19.8\%) of controls belonged to age group 31-40ears, 7 (2.1\%) case and $9(1.3 \%)$ controls belonged to age group greater than 40 year (Table 1$)$.

\begin{tabular}{|c|c|c|c|}
\hline Exposure variable & $\begin{array}{c}\text { Cases } \\
\mathrm{N}=338 \\
\text { No. }(\%)\end{array}$ & $\begin{array}{c}\text { Controls } \\
\mathrm{N}=676 \\
\text { No. }(\%)\end{array}$ & $\begin{array}{c}\text { Total } \\
\mathrm{N}=1014\end{array}$ \\
\hline $\begin{array}{l}\text { Residency } \\
\text { Rural } \\
\text { Urban }\end{array}$ & $\begin{array}{ll}218 & (64.5) \\
120 & (35.5)\end{array}$ & $\begin{array}{l}427(63.2) \\
249(36.8)\end{array}$ & $\begin{array}{l}645(63.61) \\
369(36.39)\end{array}$ \\
\hline $\begin{array}{l}\text { Maternal age } \\
<20 \text { yrs } \\
20-30 y r s \\
31-40 y r s \\
>40 y r s\end{array}$ & $\begin{array}{c}41(12.1) \\
204(60.4) \\
86(25.4) \\
7(2.1)\end{array}$ & $\begin{array}{c}122(18) \\
411(60.8) \\
134(19.8) \\
9(1.3)\end{array}$ & $\begin{array}{c}163(16.07) \\
615(60.65) \\
220(21.7) \\
16(1.58)\end{array}$ \\
\hline \begin{tabular}{|l} 
Parity \\
Primiparous \\
Multiparus \\
\end{tabular} & $\begin{array}{c}99(29) \\
239(70.7)\end{array}$ & $\begin{array}{l}270(39.9) \\
406(60.1)\end{array}$ & $\begin{array}{l}369(36.39) \\
645(63.61)\end{array}$ \\
\hline $\begin{array}{l}\text { GA } \\
\text { Preterm } \\
\text { Term } \\
\text { Post term } \\
\end{array}$ & $\begin{array}{c}5(1.5) \\
319(94.4) \\
14(4.1)\end{array}$ & $\begin{array}{c}16(2.4) \\
649(96) \\
11(1.6)\end{array}$ & $\begin{array}{c}21(2.07) \\
968(95.46) \\
25(2.47)\end{array}$ \\
\hline $\begin{array}{l}\text { Sex } \\
\text { Female } \\
\text { Male }\end{array}$ & $\begin{array}{l}138(40.8) \\
200(59.2)\end{array}$ & $\begin{array}{l}313(46.3) \\
363(53.7)\end{array}$ & $\begin{array}{l}451(44.48) \\
568(55.52)\end{array}$ \\
\hline
\end{tabular}

Table 1: Distribution of Predictor Variables versus Neonatal Birth Weight, Debre Markos Referral Hospital, Northwest Ethiopia, 2014.

\begin{tabular}{|l|c|c|c|}
\hline Complication & $\begin{array}{c}\text { Cases } \\
\mathbf{N = 3 3 8} \\
\text { No. (\%) }\end{array}$ & $\begin{array}{c}\text { Controls } \\
\mathbf{N = 6 7 6} \\
\text { No. (\%) }\end{array}$ & $\begin{array}{c}\text { Total } \\
\mathbf{N = 1 0 1 4}\end{array}$ \\
\hline Mode delivery & $152(45)$ & $365(54)$ & $517(50.98)$ \\
SVD & $91(26.9)$ & $129(19.1)$ & $220(21.7)$ \\
C/S & $91(26.9)$ & $177(26.2)$ & $268(26.43)$ \\
Instrumental & $4(1.2)$ & $5(0.7)$ & $9(0.89)$ \\
\hline Destructive & $12(3.6)$ & & $19(1.87)$ \\
\hline Complications & $90(26.6)$ & $93(13.8)$ & $183(18.05)$ \\
PPH & $8(2.4)$ & $12(1.8)$ & $20(1.97)$ \\
Perineal tear & $228(67.5)$ & $564(83.4)$ & $792(78.1)$ \\
\hline Other complication & & & \\
No complication & $314(92.9)$ & $625(92.5)$ & $939(92.4)$ \\
\hline Neonatal outcome & $24(7.1)$ & $51(7.5)$ & $75(7.6 \%)$ \\
\hline Alive & & & \\
Dead & $78(23.1)$ & $181(26.8)$ & $259(25.54)$ \\
\hline $\mathbf{1}^{\text {st }}$ min APGAR & $260(76.9)$ & $495(73.2)$ & $755(74.46)$ \\
\hline Low & & & $101(9.96)$ \\
\hline Normal & $27(8)$ & $74(10.9)$ & $913(90.04)$ \\
\hline $\mathbf{5}^{\text {th }}$ min APGAR & $311(92)$ & $602(89.1)$ & \\
\hline Low & & & \\
\hline Normal & & & \\
\hline
\end{tabular}

Table 2: Distribution of Complication versus Neonatal Birth Weight, Debre Markos Referral Hospital, Northwest Ethiopia 20014.

\section{Pregnancy related factors}

Regarding maternal parity 369 (36.4\%) of neonates were born from primiparus and $645(63.6 \%)$ of neonates were born from muliparus. Among cases and controls 99 (29.3\%) and 270 (39.9\%) respectively were from primiparus women, on the other hand 239 (70.7\%) and 406 (60.1\%) were from multiparus women. Regarding the gestational age 21 (2.1\%) of neonates were born pre-terms, 968 (95.5\%) of neonates were born at terms, 25 (2.5\%) of neonates were born post-term. Among case $5(1.5 \%)$ were born preterm, $319(94.4 \%)$ were born term and $14(4.1 \%)$ were born post term. Among controls 16 (2.4\%) were born preterm, $649(96 \%)$ were born term and $11(1.6 \%)$ were born post term (Table 1$)$.

Regarding gestational diabetes only $40(3.9 \%)$ of mother were screened, 974 (96.1\%) of mothers were not screened. Among screened mother $2(0.2 \%)$ of them were diabetic and $38(3.7 \%)$ of them were non diabetic. Among cases 2/22 (9.1\%) were diabetic and from controls none was diabetic. Regarding maternal weight gain only $6(0.6 \%)$ mothers had $5 \mathrm{~kg}$ and less weight increment, 27 (2.7\%) of mothers had 6 to $10 \mathrm{~kg}$ weight increment, only $6(0.6 \%)$ of them had weight increment between 11 to 15 $\mathrm{kg}$ and 975 (96.2\%) had no weight measurement at all. From total of study participants 152 (54\%) of cases and 365 (54\%) of controls were delivered by SVD, 91 (26.9\%) of cases and 129 (19.1\%) of controls were delivered by C/S, 91 (26.9\%) of cases and 177 (26.2\%) of controls were delivered with instrument assisted delivery, and the rest $4(1.2 \%)$ and $5(0.7 \%)$ of cases and controls respectively were delivered by destructive delivery (Table 2).

Neonatal factors: Among the study participants, 939 (92.6\%) of the participants were alive and $75(7.4 \%)$ of the participants were dead. Regarding neonatal sex, 563 (55.5\%) of the participants were male and 451 (44.5\%) of the participants were females with a male to female ratio of 1.2. Among total cases and controls 200 (59.2\%) and 363 (53.7\%) respectively were males the rest $138(40.8 \%)$ and $313(46.3 \%)$ were females respective group. Regarding the first minute APGAR score $78(23.1 \%)$ of cases and $181(26.8 \%)$ of controls were categorized as having low APGAR score and the rest 260 (76.9\%) of cases and 495 (73.22\%) of controls were categorized as having normal APGAR score. This study indicated that of the cases and controls 27 (8\%) and 270 (39.9\%) respectively were categorized as having low APGAR score at first minute on the other hand 311 (92\%) and 406 (60.1\%) were having normal APGAR score at fifth minute (Table 2). 
Citation: Wondie T, Jara D, Ayana M (2014) Factors Associated with Macrosomia among Neonates Delivered at Debre Markos Referral Hospital, Northwest Ethiopia, 2014: A Case Control Study. J Diabetes Metab 5: 468 doi:10.4172/2155-6156.1000468

Page 4 of 5

Maternal complication: Regarding maternal complication, 19 (1.9\%) of the mothers of neonates were experienced PPH, 183 (18\%) of the mothers were experienced perinatal tear, 20 (2\%) of them were experienced other complication, $792(78.1 \%)$ of them had no any experience of complication.

From total mothers of neonates cases and controls $12(3.6 \%)$ and 7 (1\%) respectively were having $\mathrm{PPH}, 90(26.6 \%)$ and 93 (13.8\%) of mothers had perineal tear, $228(67.5 \%)$ and $564(83.4 \%)$ of mothers had no maternal complication and the rest $8(2.4 \%)$ and $12(1.8 \%)$ of mothers had other type of complication in respective group (Table 2).

Associated factors with neonatal birth weight: As it can be noted from the result of the bivariate analysis, residency and neonatal sex were not significantly associated with neonatal birth weight at a 0.2 level of significance and were excluded from further analyses. Maternal parity, maternal age category and gestational age which fulfilled the minimum requirement were considered for further assessment and entered into the multivariable logistic regression model.

Consequently, the multivariable logistic regression analysis was used by taking all the associated variables into account simultaneously and only two factors remained to be significantly associated with neonatal birth weight at $5 \%$ level of significance.

Maternal parity showed a significant association with neonatal birth weight in the study. Neonates born from multiparus women were 1.44 times more likely to have macrosomia as compared to neonates born from primiparus women with $95 \% \mathrm{CI}$ of AOR $(1.05,1.98)$ and $\mathrm{p}$ value of 0.025 (Table 3 ).

Gestational age has showed a significant association with neonatal birth weight. Neonates born post term were 3.67 times more likely to be macrosomia as compared to preterm deliveries with $95 \% \mathrm{CI}$ of AOR $(1.01,13.32)$ and $\mathrm{p}$ value of 0.048 (Table 3 ).

Complications associated with macrosomia among neonates: Maternal complications were showed association with neonatal birth weight. (With $\chi_{2}$ value $=35.9, \mathrm{p}$ - value $<0.001$ ) (Table 4 ). Other factors like mode of delivery, first and fifth minute APGAR score and neonatal outcome were not associated with neonatal birth weight.

\section{Discussion}

This study was conducted to assess associated factors with macrosomia among neonates delivered at Debre Markos Referral Hospital Northwest Ethiopia, 2014. Institutional based a case control study was used to answer the research question.

The finding of this study revealed that multiparity found to have positive statistically significant association with macrosomia. This has been demonstrated in Norwegian study, Japanese, Malaysian, Nigerian and Czech Republic studies [4,9-12].

Post maturity was found to have positive statistically significant association with macrosomia which was also demonstrated in Mediterranean island community, turkey, paris, and also Tikur Anbesa study in Addis [4,13-17].

Maternal complications were positively associated with macrosomia birth outcome. This was also demonstrated in other study $[16,18]$.

The finding of this study revealed that $3.9 \%$ of mothers were screened for gestational diabetes. And about 37 (3.8\%) mothers were having weight measurement. But most studies showed gestational diabetes and maternal weight gain during pregnancy were strong predictors of macrosomia $[4,8,9,12,15,18-22]$. This paper fail to test for this predictor variable due to either documentation gap or weighing mothers and screening mothers for diabetes is less practiced in the institution. So other predictors were assessed for association. All other factors like, maternal age, neonatal sex, first and fifth minute APGAR score, mode of delivery and neonatal outcome were not showed significant association with neonatal birth weight in this study unlike other studies which show strong association for some of the variables. This may be due the population and their characteristics like socio-economics, socio-demographic and health care system difference. Limitation of this study is its retrospective nature reflected incomplete documentation of relevant variables including maternal weight measurement and maternal diabetes status.

In conclusion Multi parity and post maturity were important determinant of macrosomia. Macrosomia was significant predictor

\begin{tabular}{|c|c|c|c|c|c|}
\hline Exposure variable & $\begin{array}{c}\text { Cases } \\
N=338 \\
\text { No. }(\%)\end{array}$ & $\begin{array}{c}\text { Controls } \\
N=676 \\
\text { No. }(\%)\end{array}$ & COR with $95 \% \mathrm{Cl}$ ) & AOR with $95 \% \mathrm{Cl}$ ) & P-value \\
\hline $\begin{array}{l}\text { Maternal age } \\
<20 \text { yrs } \\
20-30 y r s \\
31-40 y r s \\
>40 y r s\end{array}$ & $\begin{aligned} 41 & (12.1) \\
204 & (60.4) \\
86 & (25.4) \\
7 & (2.1)\end{aligned}$ & $\begin{array}{c}122(18) \\
411(60.8) \\
134(19.8) \\
9(1.3)\end{array}$ & $\begin{aligned} & 1 \\
& 1.48(0.0 .99,2.19) \\
& 1.9(1.22,2.98) \\
& 2.3(0.81,6.61)\end{aligned}$ & $\begin{array}{c}1 \\
1.23(0.81,1.87) \\
1.43(0.87,2.38) \\
1.67(0.56,4.94)\end{array}$ & $\begin{array}{l}0.334 \\
0.158 \\
0.352\end{array}$ \\
\hline $\begin{array}{l}\text { Parity } \\
\text { Primiparous } \\
\text { Multiparus }\end{array}$ & $\begin{array}{c}99(29) \\
239(70.7)\end{array}$ & $\begin{array}{l}270(39.9) \\
406(60.1)\end{array}$ & $\begin{array}{c}1 \\
1.61(1.21,2.13)\end{array}$ & $\begin{array}{c}1 \\
1.44(1.05,1.98)\end{array}$ & $0.025^{\star}$ \\
\hline $\begin{array}{l}\text { GA } \\
\text { Preterm } \\
\text { Term } \\
\text { Post term }\end{array}$ & $\begin{array}{c}5(1.5) \\
319(94.4) \\
14(4.1)\end{array}$ & $\begin{array}{c}16(2.4) \\
649(96) \\
11(1.6)\end{array}$ & $\begin{array}{c}1 \\
1.57(0.57,4.33) \\
4.07(1.14,14.61)\end{array}$ & $\begin{array}{c}1 \\
1.40(0.5,3.89) \\
3.67(1.01,13.32)\end{array}$ & $\begin{array}{l}0.517 \\
0.048^{*}\end{array}$ \\
\hline
\end{tabular}

*Significant association, the overall significance is given by their corresponding $\mathrm{P}$ - values

Table 3: Multivariable Analysis of Neonatal Birth Weight Versus Some Predictors Debre Markos Referral Hospital Northwest Ethiopia 2014.

\begin{tabular}{|l|c|c|c|}
\hline Complication & $\begin{array}{c}\text { Macrosomic } \\
\mathbf{N = 3 3 8}\end{array}$ & $\begin{array}{c}\text { Normal birth } \\
\mathbf{N = 6 7 6}\end{array}$ & $\begin{array}{c}\mathbf{X}^{2} \text { value } \\
\text { Linear by linear }\end{array}$ \\
\hline PPH & 12 & 7 & \\
Perineal tear & 90 & 93 & \\
Other cmplication & 8 & 12 & \\
No complication & 228 & 564 & \\
\hline
\end{tabular}

Table 4: Chi-Square Table Neonatal Birth Weight Versus Complication In Debre Markos Referral Hospital North West Ethiopia, 2014. 
Citation: Wondie T, Jara D, Ayana M (2014) Factors Associated with Macrosomia among Neonates Delivered at Debre Markos Referral Hospital, Northwest Ethiopia, 2014: A Case Control Study. J Diabetes Metab 5: 468 doi:10.4172/2155-6156.1000468

Page 5 of 5

of maternal complications. Based on the findings of the study, the following recommendations are forward:

- Maternal weight measurement, gestational diabetic screening and documentation should be standard of care in caring pregnant mothers in this hospital.

- Multi parus women and post-term pregnancy should be focused to decrease the incidence of neonatal macrosomia.

- Multiparus women and post term pregnancies should be screened for macrosomia to detect early and prevent associated maternal complication.

- Health institutions attending the delivery of a macrosomia baby should be ready for caring maternal complication associated with macrosomia.

\section{Acknowledgement}

Our deepest gratitude goes to Department of Public Health, Medicine and Health sciences college, Debre Markos University College for proper review and approval of this paper. We also thank Ethiopian pediatric society for funding this research; DMRH pediatrics wards professionals and data collectors for their cooperation and assistance. Our Special thanks goes to staff members for their unlimited contribution and support for the success of this paper.

\section{References}

1. Portella PR (1999) Fetal macrosomia: Definition, Prediction, Risk and Prevention. Obstetrics and Gynecology (peru) 39: 42-50.

2. Ezegwui HU1, Ikeako LC, Egbuji C (2011) Fetal macrosomia: obstetric outcome of 311 cases in UNTH, Enugu, Nigeria. Niger J Clin Pract 14: 322-326.

3. Islam R (2012) Prevalence and Predictors of Macrosomia Newborn: NorthernNorwegian Mother-and-Child Study [A Thesis for the Degree of Master in Public Health]: university of tromsq.

4. Koyanagi A, Zhang J, Dagvadorj A, Hirayama F, Shibuya K, et al. (2013) Macrosomia in 23 developing countries:an analysis of a multicountry, facilitybased, cross-sectional survey. The Lancet 381: 476-483.

5. Savona-Ventura C, Chircop M (2004) Determinants for Macrosomia in a Mediterranean Island community. Int J Diabetes \& Metabolism 12: 44-48.

6. Abramowicz Js, ahn JT. UpToDate 2011.

7. (2011) Ethiopia Demographic and Health Survey Central Statistical Agency Addis Ababa, Ethiopia, ICF International Calverton, Maryland, USA
8. Najafian M, Cheraghi M (2012) Occurrence of fetal macrosomia rate and its maternal and neonatal complications: a 5-year cohort study. ISRN Obstet Gynecol 2012: 353791.

9. Ezegwui HU, Ikeako LC, Egbuji C (2011) Fetal macrosomia: obstetric outcome of 311 cases in UNTH, Enugu, Nigeria. Niger J Clin Pract 14: 322-326.

10. VÄtr M (2005) [Risk factors associated with high birthweight deliveries]. Ceska Gynekol 70: 347-354.

11. Morikawa M, Cho K, Yamada T, Yamada T, Sato S, et al. (2013) Fetal macrosomia in Japanese women. J Obstet Gynaecol Res 39: 960-965.

12. Yadav H, Lee $\mathrm{N}$ (2014) Factors influencing macrosomia in pregnant women in a tertiary care hospital in Malaysia. J Obstet Gynaecol Res 40: 439-444.

13. Oral E, CaÄ̈̈daÅŸ A, Gezer A, Kaleli S, Aydinli K, et al. (2001) Perinatal and maternal outcomes of fetal macrosomia. Eur J Obstet Gynecol Reprod Biol 99: 167-171.

14. Bobba E, Fascendini M, Bertino E (2004) Impact of pregnancy and labour complications on neonatal outcomes: a retrospective cohort study in a rural hospital of Ethiopia.

15. Savona-Ventura C, Chircop M (2004) Determinants for Macrosomia in Mediterranean Island community. Int J Diabetes \& Metabolism 12: 44-48.

16. Admassu G, Gaym A (2009) Outcome of pregnancy complicated by diabetes at Tikur Anbessa Hospital, Addis Ababa Ethiopia - A five year review. Ethiopian Journal of Reproductive Health 3.

17. Batallan A, Goffinet F, Paris-Llado J, Fortin A, Bréart G et al. (2002) Fetal macrosomia: management, obstetrical and neonatal results. Multicenter casecontrol study in 15 maternity hospitals in Paris and the lle de France area. Gynecol Obstet Fertil 30.

18. Anya S, Anya A (2006) Macrosomia: a case-control study of risk factors and outcome. Highland Medical Research Journal 4.

19. Dennedy MC, Dunne F (2013) Macrosomia: defining the problem worldwide. Lancet 381: 435-436.

20. Kamanu Cl, Onwere S, Chigbu B, Aluka C, Okoro O, et al. (2009) Feta macrosomia in African women: a study of 249 cases. Arch Gynecol Obstet 279 : 857-861.

21. Martin T, Clarke A (2003) A case control study of the prevalence of perinata complications associated with fetal macrosomia in Antigua and Barbuda. West Indian Med J. 52: 231-234.

22. Gu S, An X, Fang L, Zhang X, Zhang C, et al. (2012) Risk factors and long-term health consequences of macrosomia: a prospective study in Jiangsu Province China. J Biomed Res 26: 235-240. 